\title{
AUGUSTO E O MODELO DE BONUS PRINCEPS NO DE CLEMENTIA DE SÊNECA
}

\author{
Augustus and the bonus princeps model at Seneca's De Clementia
}

\section{Taynam Santos Luz Bueno ${ }^{1}$}

\begin{abstract}
RESUMO
Pretende-se expor, neste artigo, o papel de Augusto como exemplo para Nero, sob a óptica do De Clementia de Sêneca. Enfatizar-se-á, como veremos, o modo peculiar com que o filósofo romano retoma Otaviano. Tratase, para Sêneca, de trazer à tona a imagem do primeiro imperador enquanto homem em detrimento daquela divinizada, exaltando suas habilidades políticas e seu modo de solucionar problemas práticos em detrimento do exercício de sua clemência que, na concepção do autor romano, não constitui verdadeira virtude, pois está distante dos preceitos morais fundamentados pelo estoicismo. Isto é, Otaviano terá uma ambígua invocação enquanto exemplo pois, se por um lado deverá ser levado em consideração, graças à sua genial capacidade de articulação e resolução de conflitos, enquanto exemplo moral deverá ser tomado com precaução, uma vez que Augusto cedeu às paixões, afastou-se da ratio e, portanto, não se mostrou um governante ideal do ponto de vista da doutrina estoica. Em suma, procura-se evidenciar, neste texto, que Augusto, apesar de sua exemplaridade no negotium romano, não deve ser considerado paradigma da moralidade para Nero, tal qual o sapiens estoico.
\end{abstract}

Palavras-chave: Sêneca. De Clementia. Augusto. Filosofia Política. Estoicismo

\begin{abstract}
It's intended to expose, in this article, the role of Augustus as an example for Nero, from the perspective of Seneca's De Clementia. As we will emphasize, we will take the peculiar way in which the Roman philosopher takes up the image of Octavian. For Seneca, it's a question of bringing to light the image of the first emperor as a "man" at the expense of that deified, extolling his political ability and his way of solving practical problems, at the same time that refuse Augusto's clemency, which, in the view of the Roman author, does not constitute true virtue, as it's distant from the moral precepts of the stoicism. That is, Otaviano will have an ambiguous invocation as an example because, on the one hand, he should be taken into consideration,

\footnotetext{
${ }^{1}$ Professora Adjunta da Universidade Federal de Alagoas.

E-mail: taynam.bueno@ichca.ufal.br. ORCID: https://orcid.org/0000-0002-2416-0282
} 
thanks to his genius ability to articulate and resolve conflicts, but while a moral example he should be taken with caution, since Augusto gave in to the passions, departed from the ratio and, therefore, did not prove to be an ideal ruler from the point of view of Stoic doctrine. In summary, we try to show, in this text, that Augusto, despite his exemplum in the Roman negotium, should not be considered a paradigm of morality for Nero, like the Stoic sapiens.

Keywords: Seneca. De Clementia. Augustus. Political Philosophy. Stoicism.

A imagem de Augusto, no De Clementia ${ }^{2}$, possui aspectos contrapostos. Ora o primeiro dos imperadores de Roma é apresentado como cruel e sanguinário, ora é apresentado como ponderado e valoroso. É preciso, portanto, compreender os possíveis motivos que levam Sêneca a compor deste modo a imagem de Augusto no Tratado sobre a Clemência, analisando com cautela em que medida o primeiro imperador serve de exemplum para o jovem Nero, bem como em que circunstâncias o autor romano o rejeita como modelo para o futuro imperador. O objetivo principal deste texto é, portanto, investigar qual o papel de Augusto na formação moral e política de Nero no contexto do De Clementia, assim como quais seriam os limites deste exemplum no conjunto da reflexão política de Sêneca, tendo em vista sua inspiração estoica.

A figura do primeiro dos imperadores romanos ${ }^{3}$ é constantemente lembrada por Sêneca em seus textos, fato que faz com que Augusto seja muitas vezes citado no conjunto de sua obra, não somente no De Clementia, mas também em diversos outros textos, incluindo suas peças de teatro, consolações e cartas. De acordo com Jal (1957, p.245), a quantidade total destas citações ultrapassa o número de quarenta sendo que, na maior parte delas, o julgamento do filósofo a respeito da figura do primeiro imperador é afirma-

\footnotetext{
${ }^{2}$ Texto escrito por Sêneca no início do governo de Nero (37-68 d.C), provavelmente entre o final do ano de 55 d.C e o ano de 56 d.C. O texto em questão foi traduzido para o portu guês por Ingeborg Braren sob o título de Tratado sobre a clêmencia. (Petrópolis: Vozes, 2013). Neste artigo utilizaremos tal tradução, salvo indicação contrária. Para comparação e citações latinas, consultamos também a versão de Susanna Braund (Seneca, De Clementia. Edited with translation and commentary by Susanna Braund. Oxford: Oxford University Press, 2009). Para maiores informações acerca da data e composição do texto, consultar (BRAUND, 2009. p.16), (ALBERTINI, 1923, pp. 69-73; 150-155; 262-264), (KINDLER, 1966, pp. 39-60) e (MORTUREUX, 1973).

${ }^{3}$ Trata-se de Otaviano, depois denominado Augusto, que exerceu o poder de 27 a.C até 14 d.C e acumulou diversos títulos e honrarias.
} 
do positivamente. Em geral, a imagem de Augusto aparece, no conjunto dos escritos de Sêneca, atrelada a atributos positivos e virtudes, tais como inteligência, sabedoria, coragem, paciência, nobreza de conduta e sobretudo - e o que mais nos interessa - clemência ${ }^{4}$. Na maioria das passagens dos textos de nosso filósofo, sobressai a nítida estima que Sêneca nutria por Augusto, este que, como sabemos, gozava de elevada admiração entre os romanos. Afinal, não devemos esquecer, Augusto nunca descuidou da construção de sua imagem, tendo legado, tanto por meio de vasta iconografia, quanto por meio da pena de poetas e historiadores tais como Virgílio, Horácio, Propércio, Tibúlo, Tito Lívio, verdadeiro mito a respeito de si. Assim, muito do mito acerca de Augusto, amplamente transmitido ao longo dos séculos, seja por seus poetas, seja por seus historiadores, certamente influenciou Sêneca na construção de seus textos, bem como ajudou a consolidar a imagem do imperador romano como exemplo de bom governante por muitos séculos.

No caso específico de Sêneca, a motivação dos elogios do filósofo romano à figura de Augusto é diversa e, por muitas vezes, contrapõe comentadores e interpretações. Em alguns casos, devemos igualmente lembrar, Augusto também é criticado ou minimizado frente ao primeiro dos imperadores, fato que levou a crítica a fornecer diversas interpretações diferentes. Alguns, como Préchac (1921) e Waltz (2013), sustentam em seus textos que Augusto foi o modelo ideal de governante para Sêneca, modelo capaz de guiar de forma eficaz e moralmente elevada Nero em sua jornada política. Outros estudiosos da antiguidade, tais como Jean Béranger (1943-

${ }^{4}$ A clemência não constituía uma virtude cardinal no período anterior à Sêneca, como as quatro outras virtudes sempre mencionadas: a prudência, justiça, coragem ou moderação, mas, no entanto, era uma virtude que fora fortemente atrelada ao Augusto. A Clementia era, ao lado de uirtus, iustitia e pietas, virtudes próprias de Augusto, como nos testemunham as Res GestaeXE "Res Gestae", virtudes pelas quais o imperador gostaria de se fazer lembrar (C.f. Augusto, Res Gestae Diui Augusti, 34, 2.). É preciso lembrar ainda que a conceitualização da palavra clementia só se dá efetivamente com Sêneca, para quem tal virtude transforma-se em atividade estritamente racional e distancia-se do campo semântico de palavras como misericordia, lenitas, venia, mansuetudo e indulgentia (Para um estudo deste vocabulário, procurar o trabalho de LACHAPELLE, 2011). Para o autor romano, clementia é, portanto, fruto exclusivo da razão. É ato racional. A própria palavra clemência, como bem nos indica Tácito e nos confirma o comentador Pierre Grimal, "serviu de condutora à propaganda governamental durante seus primeiros anos de império. É certo que, a atribuição de uma das virtudes principais do estoicismo ao príncipe fora, da parte de Sêneca, um ato calculado. Este movimento teria sido iniciado nos tempos de Augusto, com os clupeus uirtutis; mas o que era naquele tempo uma homenagem ocasional, é agora erguido como sistema." (GRIMAL, 1979. p.241). 
1944, pp.144-145.), mostraram que Sêneca quis fazer de Augusto o modelo ideal para Nero, mas foi incapaz, dado as ações precedentes e faltas morais do primeiro dos imperadores romanos. Outros comentadores ainda, como Jal (1957), indicaram que não se tratava de uma incapacidade de fazer de Augusto o modelo ideal, mas sim que Sêneca, propositalmente, procurou pintar e construir a imagem do primeiro princeps em seus exempla de forma deteriorada ou rebaixada, visando retoricamente enfatizar os vícios e a crueldade de Augusto e, ao mesmo tempo, elevando a imagem de Nero frente aos seus antecessores. Pedagogicamente falando, a intenção de Sêneca ao rebaixar a imagem de Augusto seria, na visão deste comentador, encaminhar o jovem imperador Nero para o caminho da verdadeira clemência, diferente da falsa clemência declarada pelo autor das Res Gestae. Afinal, aos olhos de nosso autor, em contraposição à clemência exercida por Augusto, Nero promovia verdadeira paz. Nas palavras do autor romano: "Eu não dou o nome de clemência a uma crueldade frouxa. A verdadeira clemência, César, é essa que tu desempenhas." (Sêneca, De Clem. I, 11, 2).

No De Clementia, como já foi dito, algumas vezes Augusto figura como modelo a ser seguido por Nero, outras não. Apenas trazendo à tona um exemplo da importante relação existente entre Augusto e Nero, vale lembrar das passagens onde Suetônio reproduziu aquele que seria o discurso de posse do jovem imperador (discurso certamente escrito por Sêneca ${ }^{5}$, em data muitíssimo próxima da escritura do De Clementia), discurso no qual Nero prometia que, durante seu império, governaria “ex praescriptio Augus$t i$ " (SUETÔNIO, Nero, 10, 1), isto é, de acordo com os preceitos e determinações comumente atribuídos ao governo de Augusto. Em outras palavras, neste discurso Nero comprometia-se a governar alinhado aos ideais que ainda estavam fortemente ligados à figura do primeiro dos imperadores, tais como o retorno à inspiração constitucional do principado (graças ao aumento do poder do senado), reformas sociais e demais medidas que visavam restituir as bases da antiga república. Uma vez que Augusto, no momento da instauração do principado, o fundamentou em bases republicanas, conservando antigas instituições e regimentos oriundos ainda da antiga república,

${ }_{5}^{5}$ O historiador Dião Cássio (Hist. Rom., LXI, 3) é quem indica que Sêneca é o autor do discurso. 
não deveria ser desprezado enquanto modelo político. Nas palavras de Vizentin:

Ao assumir o poder em 54 (Tácito. Anais XIII, 69; Suetônio. Vida de Nero VIII; e Dião Cássio. História Romana, LXI, 3, 1), Nero revela, em seu primeiro discurso como imperador uma singular mudança em relação aos métodos de governo de Cláudio, rejeitandoos. Promete retornar ao modelo de Augusto, honrar a integridade do Senado, abolir os crimes de traição (maiestas) e as decisões antes tomadas no âmbito privado do príncipe, além de afastar os libertos do poder. (VIZENTIN, 2005. p. 45)

Augusto, neste sentido, sempre fora festejado enquanto um ótimo imperador e um restaurador das instituições republicanas (VIZENTIN, 2005, pp.34-45) e, portanto, não deveria ser desprezado enquanto modelo para o novo governo. No entanto, alerta Sêneca, mesmo o mais celebrado dos imperadores da dinastia julio-claudiana não é imaculado e Nero, caso queira garantir a legitimação e a manutenção de seu poder, deverá, além de governar de acordo com os preceitos comumente atribuídos à Augusto, fundamentá-lo e exercê-lo com base na filosofia estoica, revelando-se, portanto, princeps virtuoso, verdadeiramente clemente, e capaz de agir de acordo com a ratio.

Deste modo, Sêneca parece buscar, no De Clementia, uma forma de instigar Nero a ter prudência ao tomar por modelo Augusto, pois até mesmo o mais aclamado de seus antecessores não era livre de deslizes morais. Afinal, Sêneca nos lembra a todo instante, também Augusto tinha as mãos sujas de sangue. Se Augusto fora muitas vezes retratado como excelente mediador de conflitos, ótimo governante e exímio solucionador de problemas práticos, moralmente falando (e pensando na esteira da filosofia estoica) era necessário ter cautela em adotá-lo cegamente como modelo norteador de suas ações. Augusto, segundo os relatos de Sêneca, afastou-se muitas vezes dos ideais estoicos ao ceder às paixões e não tomar suas decisões fundamentadas única e exclusivamente na razão - Sêneca lembra a todo instante que Augusto não é, portanto, um sapiens ${ }^{6}$.

${ }^{6} \mathrm{O}$ sábio difere do insensato por suas ações, pela conformidade que mantém com a natureza, pois, como sabemos, "o bem supremo consiste em viver de acordo com a Natureza" C.f. Sêneca. De Otio. V, 1. (Solemus dicere summum bonum esse secundum naturam uiuere: natura nos ad utrumque genuit, et contemplationi rerum et actioni.). Viver de acordo com a Natureza equivale dizer, segundo os estoicos, que o fim último de cada ser vivo é viver conciliando-se (oikeiosis) tanto à sua própria Natureza, quanto à physis universal, constan- 
Corroboram as críticas de Sêneca, neste contexto, os escritos de Tácito a respeito das controvérsias existentes acerca da pax augusta, que nem sempre despertaram opiniões convergentes no tocante a sua efetiva instituição no império. O historiador romano nos diz que, entre os contemporâneos de Augusto, muitos eram aqueles que viam na famosa pax augusta, uma pax cruenta - ou uma paz sangrenta ${ }^{7}$. Isto é, Tácito denuncia, muito tempo antes de Sêneca fazer referência à crueldade e a sede de vingança de Augusto em seu De Clementia que, na verdade, a pax imposta por Augusto fora a pax das conjurações e das execuções de seus adversários políticos, e não a pax perfeita e conciliadora preconizada nas Res Gestae ${ }^{8}$. Sêneca traz à tona as conjurações promovidas por Augusto ao dizer que:

no período de perturbação geral do Estado, [Augusto] empunhou a espada quando tinha a idade que tu [Nero] tens agora, tendo começado seu décimo oitavo ano de vida. Tendo passado seu vigésimo ano, já tinha enterrado o punhal no peito de seus amigos, já tinha procurado golpear traiçoeiramente o flanco do cônsul Marco Antônio e já tinha sido seu colega de proscrições. (SÊNECA, De Clem. $\mathrm{I}, 9,1)$

Na obra do filósofo romano, portanto, a clemência de Augusto (virtude cujo o imperador tanto se vangloriava em suas Res Gestae), é minorada e colocada em questão por Sêneca, enfraquecendo pouco a pouco o mito criado entorno do primeiro dos príncipes em favor de $\mathrm{Nero}^{9}$. Assim, ao mesmo tempo em que nosso autor contrapõe a verdadeira virtude de Nero em detrimento de Augusto, Sêneca ainda forja o conceito de clemência nos moldes da filosofia estoica, alinhando-a à mais alta qualidade que um bom governante deve possuir. Não somente a clementia serve, neste contexto, para diferenciar Augusto de Nero, quanto, no pensamento de Sêneca, tal virtude se mostra efetivamente distintiva da própria proeminência do princeps, capaz,

temente atualizando-a. Viver de acordo com a natureza, para o homem e contrariamente aos animais seria, portanto, viver de acordo com a razão, dado que a racionalidade é uma carac terística humana que deve ser levada à perfeição. Seria uma espécie de apropriação de si mesmo, apropriação das qualidades e características que são exclusivas daquele ente vivo (oikeiosis).

7 Tácito, Ann., I, 10, 3. Em latim: "Pacem sine dubio post haec, verum cruentam".

${ }^{8}$ Há uma tradução para o português deste texto na seguinte indicação: Augusto, $A$ vida e os feitos do Divino Augusto (Res Gestae Diui Augusti). Tradução de Matheus Trevizam, Paulo Sérgio Vasconcellos, Antônio Martinez de Rezende. Belo Horizonte: Editora UFMG, 2007.

9 Do ponto de vista retórico, tal procedimento de rebaixamento de assuntos ou temas elevados em favor de outro ou de algum ponto de vista é típico do método da Diatribe, método também utilizado por Sêneca. 
portanto, de legitimar o próprio modelo de poder existente em Roma naquela ocasião.

Mas nem somente de críticas a Augusto é formada a obra de Sêneca, como já dito. Afinal, tratando especificamente do De Clementia, é possível perceber que, no geral, a imagem construída acerca de Augusto adquire caráter positivo, mesmo que o primeiro dos imperadores não seja por completo idealizado por nosso filósofo. Tratam-se, como veremos, de elogios voltados ao modo como Augusto conduzia administrativamente o império, elogios a sua conduta no negotium romano ${ }^{10}$. É claro que não se pode deixar de lado a crítica moral feita por Sêneca no De Clementia à Augusto, mas, politicamente falando, seu modelo de governo permanece sendo um bom exemplo para o jovem Nero $^{11}$. Basta perceber a clara divisão na forma de retratar Augusto, existente na obra em questão, que o representa em dois momentos distintos: Sêneca retrata Augusto de uma forma em sua juventude e de outra em sua idade mais madura. É como se pudéssemos delimitar dois princeps diferentes na mesma figura histórica, Otaviano e Augusto. O primeiro, Otaviano (ou o jovem Augusto), rende-se facilmente à ira, à vingança e demonstra poucos momentos de verdadeira clemência - É o imperador das conjurações, da batalha de Actium e dos assassinatos e está, portanto, afastado dos ditames da moral estoica. Ao contrário, quando atinge idade mais avançada e recebe o título de Augusto, Otaviano passa a ser, então, retratado de forma mais afável, sendo descrito como clemente, meigo (De Clem. I, 9, 1) e adjetivado como um verdadeiro Deus (De Clem. I, 10, 3). É o que nos é bem retratado no trecho a seguir:

$\mathrm{Na}$ juventude, [Augusto] inflamou-se e a cólera o arruinou; fez muitas coisas às quais voltava os olhos constrangido. Ninguém ousará comparar a tua mansidão [de Nero] à do divino Augusto, mesmo se fossem levados à disputa os teus anos juvenis e a velhice dele, mais do que madura. Terá sido moderado e clemente; por certo depois de tingir o mar com sangue romano na batalha de Ácio,

\footnotetext{
10 Não é nosso intuito, neste texto, propor a separação da ética e da política na antiguidade, mas apenas indicar as diversas facetas do exemplum de Augusto no Tratado sobre a clemência de Sêneca. Devemos, portanto, lembrar que, na antiguidade e no contexto da filosofia política, o bom governo é necessariamente o governo virtuoso e moralmente elevado.

11 c.f. os exemplos dados, sobretudo, em De Clementia. I, 9, 2, quando Sêneca trata do caso de Lúcio Cina, acusado de conspiração contra Augusto e em De Clementia. I, 10, 1, trecho no qual Sêneca enumera alguns nomes de pessoas que foram agraciadas pela clemência deste imperador.
} 
por certo depois de destroçar frotas na Sicília, não só as suas como as do inimigo; por certo depois dos holocaustos de Perúsia e das proscrições. (SÊNECA, De Clem. I, 11, 1)

Sêneca, nesta passagem, parece mostrar a superioridade de Nero, visto que este, ainda muito jovem, já dispunha da mesma clemência e virtude que Augusto demonstrava em idade avançada ${ }^{12}$. Nero, em outras palavras, revela-se governante perfeito e sem máculas; sem as intemperanças típicas da primeira idade. Nosso autor, a partir de então, estabelece uma espécie de quadro comparativo entre Augusto e Nero, descrito entre os capítulos 9-11 do Livro I do De Clementia, quadro que, no entanto, tem como resultado a exaltação da figura de Nero em detrimento de seu antecessor, como retoricamente já era esperado. Afinal, segundo Sêneca, é preciso transformar em hábito o que é natural em Nero. Tratam-se de príncipes de naturezas diferentes, sendo a natureza de Nero superior e racional - moralmente alinhada aos ditames do pórtico. É o que nos diz Sêneca:

Mas tu [Nero] te impuseste um enorme encargo. Ninguém fala mais do divino Augusto, nem dos primeiros tempos de Tibério César, nem, querendo imitar um modelo, procura outro além do teu: avalia-se o seu principado por esta prova. Isto teria sido difícil, se a bondade não fosse natural em ti, mas encenada de vez em quando. Pois ninguém pode sustentar uma máscara durante longo tempo. Muito cedo, as coisas fingidas recaem em sua própria natureza. (SÊNECA, De Clem. I, 1, 6)

Em suma, do ponto de vista moral e de acordo com a filosofia estoica, parece que o comportamento de Augusto não serve como modelo para o jovem Nero pois, como muitos dos exemplos dados por Sêneca nos indicam, Otaviano muitas vezes cedeu às paixões e afastou-se dos ditames da clementia, sobretudo em tenra idade, ao contrário de Nero, que desempenha "a verdadeira clemência" e que, "não tendo arrependimento de sevícias praticadas, começa [sua vida política] sem qualquer mácula, sem nunca ter derramado sangue civil." ${ }^{13}$ Isto é, Nero é o detentor da verdadeira clemência, pois sua virtude é racionalmente estabelecida, estoicamente construída. Moralmente,

\footnotetext{
${ }^{12}$ No contexto do De Clementia, Nero teria uma natureza virtuosa, revelando um caráter naturalmente régio. Sobre a análise desta comparação, ver Mortureux, B. Recherches sur le De Clementia de Sénèque. Col. Latomus. Volume 128, Revue d'Études Latines. Bruxelle: 1973. p.33-34.

13 Sêneca, De Clementia. I, 11, 2. - Não entraremos aqui nas polêmicas envolvendo o assassinato de Britânico.
} 
Sêneca diz que até mesmo o divino Augusto falhou, afastando-se da razão e da clemência e cedendo espaço para as nefastas paixões, fato inadmissível na construção de um bom governante estoico. Sêneca nos retrata, portanto, o caráter humano de Augusto. É Augusto, o homem - e, portanto, falível -, que é retomado no De Clementia, e não a imagem divinizada de Augusto.

Ainda assim, mesmo que nosso autor exalte alguns exemplos de crueldades cometidas por Augusto em sua juventude, o modelo político e administrativo que tal figura traz no conjunto da obra é positivo e deve ser levado em consideração. Sêneca, no De Clementia, recupera sistematicamente o modelo de governo de Augusto, exaltando suas prerrogativas ao mesmo tempo em que as amplia e as fundamenta com os acréscimos da filosofia estoica ${ }^{14}$. A união do modelo de Augusto com a filosofia estoica é expressa, sobretudo, na exaltação e na sistematização da noção de Clementia, nunca antes feita na história romana ${ }^{15}$. A retomada da figura de Augusto, indicada no livro de Sêneca, como já mencionamos, confere ao princeps virtudes, dentre elas, a própria ideia de clemência como qualidade moral determinante para o bonus princeps. No entanto, a partir dos escritos de Sêneca, não se trata de qualquer clemência, mas da verdadeira clemência diga-se inclusive, da clemência que é fruto direto da razão, que é virtude. Não se trata, deste modo, de simples indulgência passional, mas de virtude que "se aproxima da razão", conforme nos diz Sêneca (De Clem. II, 5, 1).

Sêneca parece propor, portanto, o ressurgimento da figura de Augusto enquanto modelo de ação pública, de bom senso e boa atuação administrativa. Afinal, Augusto é exemplo de excelente administrador público e solucionador de conflitos, como nos fica claro ao longo do texto trabalhado $^{16}$. No entanto, na comparação dos dois imperadores, Sêneca exaltará as

\footnotetext{
14 Sobre a relação dos filósofos estoicos com a política conferir: Veillard, C., "A Marca do estoicismo na política romana”. In: Ler os estoicos. São Paulo: Edições Loyola, 2013, bem como o excelente livro de Valéry Laurand, La politique stoïcienne. Paris: Presses Universitaires de France - PUF, 2005.

15 Pois, devemos nos lembrar, ainda que autores anteriores a Sêneca, como Cícero por exemplo, utilizem a noção de clementia, o fazem sem sistematização. É somente com Sêneca que a clemência atingirá seu estatuto de virtude cardinal, ocupando posição de verdadeiro destaque. C.f. (BUENO, 2020).

16 Vejamos, por exemplo, a passagem onde o autor romano nos traz a narração do perdão de Lúcio Cina (Clem. I, 9), nobre que conspirava contra Augusto e que fora, antes de executar seus planos, descoberto e denunciado. Neste exemplo, Sêneca nos lembra que Augusto recorreu à razão, ponderando acerca da pena que Cina receberia por seu delito e, na medida em que aceitou alguns dos conselhos de sua esposa, resolveu agraciar o conspirador
} 
características naturalmente régias de Nero, dando ênfase às qualidades morais do novo imperador e lembrará dos excessos passionais de Augusto, sobretudo em sua juventude. Sob a óptica do De Clementia e no contexto da organização política do principado, Nero deveria, portanto, ser celebrado como o verdadeiro restaurador da legalidade, das instituições e da moralidade elevada, estabelecendo grande contraste frente aos abusos praticados por seus antecessores. O De Clementia, neste sentido, busca oferecer uma fundamentação moral do poder baseada na virtude de Nero, sua verdadeira clemência. Unindo, assim, a excelência moral de Nero às prerrogativas administrativas de Augusto, Sêneca nos lega um conjunto de reflexões capazes de guiar virtuosamente o império. Pois, além de virtuoso do ponto de vista moral, o governo de Nero, para Sêneca, ainda seria acertado do ponto de vista político e legal, estando plenamente de acordo com as antigas instituições romanas e com o modelo de governo professado por Augusto sem, no entanto, recair em seus desvarios.

Recebido em 05/01/2021 e aprovado em 30/01/2021

\section{Referências}

ALBERTINI, E. La composition dans les ouvrages philosophiques de Sénèque. Paris : (Bibliothèque des Écoles françaises d'Athènes et de Rome, fasc. 127), 1923.

AUGUSTO. Res Gestae Diui Augusti. A vida e os feitos do divino Augusto. Tradução: Matheus Trevizan, Paulo Sérgio Vasconcellos e Antônio Martinez de Rezende. Belo Horizonte: Editora UFMG, 2007.

BÉRANGER, J. "Pour une définition du Principat". In: Révue des Études Latines, tomos XXI-XXII. pp. 144-154. 1943-1944.

BUENO, T.S.L. "Manutenção e Legitimação do Poder em Sêneca: A Clemência como Atributo do Bom Governante". In: Perspectiva Filosófica, vol. 47 , n. 1,2020

CÁSSIO, Dião. História Romana, Volume IV: Livros 71-80. Tradução: Earnest Cary. Cambridge: Loeb Classical, 1990.

com a clemência, minimizando conflitos e conduzindo com sabedoria o desfecho do caso. Desde então, segundo o filósofo romano, Augusto não mais fora alvo de atentados e tinha Cina como "o mais amigo e o mais fiel", transformando definitivamente seu caráter conspirador. C.f. Sêneca, De Clem. I, 9, 12. 
FILODEMO. Filodemo: Il buon re secondo Omero. Editor: Dorandi T. Nápoles: Bibliopolis, 1982.

GRIMAL, P. Sénèque ou la conscience de l'Empire. Paris: Les Belles Lettres, 1979.

JAL, P. "Images d'Auguste chez Sénèque", In: R.E.L. (Revue des études latines), 37. 1957. pp. 242-264.

KINDLER, A. L. "Problemas de composicion y estructura en el De Clementia". In : Emerita. 34. Fasc. 1 ${ }^{\circ}$. 1966. pp-39-60.

LACHAPELLE, G. F. Recherches sur la notion de clémence à Rome du début du Ier. siècle a.C à la mort d'Auguste. Bourdeaux: Ausonius Éditions, 2011

LAURAND, V. La politique stoïcienne. Paris: Presses Universitaires de France - PUF, 2005.

MORTUREUX, B. Recherches sur le De Clementia de Sénèque. Col. Latomus. Volume 128, Bruxelle: Revue d'Études Latines. 1973

PRÉCHAC, F. Sénèque - De la Clémence. (Introduction). La traité De Clementia, sa composition et sa destination. Paris: Les Belles Lettres. 1921.

SÊNECA. Tratado sobre a clemência (De clementia). Introdução, tradução e notas: I. Braren. Petrópolis: Vozes, 1990

. De Clementia. Tradução, edição e comentários: Susanna Braund. $\overline{\text { Oxford }}$ : Oxford University Press, 2009.

. De Otio (Sobre o ócio). Tradução, apresentação e notas: José Rodrigues Seabra Filho. Edição Bilíngue. São Paulo: Nova Alexandria, 2001.

. Epistulae Morales (Cartas a Lucílio). Tradução e notas: J. Segurado e Campos. $4^{a}$ edição. Lisboa: Fundação Calouste Gulbenkian, 1991.

SUETONIO, Les vies des douze Césars. Tradução e notas: Henri Ailloud. Paris: Gallimard Folio Classique, 2014.

TACITO, Oeuvres Completes. (La germanie - Dialoque des Orateurs Histoires - Annales). Textes traduits, presentes et annotes: Pierre Grimal. Bibliotheque de la Pleiade n. 361. Paris: Gallimard, 1990.

VEILLARD, C., "A Marca do estoicismo na política romana". In: INWOOD, Brad. Ler os estoicos. São Paulo: Edições Loyola, 2013.

VIZENTIN, M. Imagens do poder em Sêneca: Estudo sobre o De Clementia. São Paulo: Ateliê Editorial, 2005. 
Perspectiva Filosófica, vol. 48 n. 2, 2021

WALTZ, R. La vie politique de Sénèque. Paris: Ed. Laville, 2013.

XENOFONTE. Cyropaedia. Tradução e notas: Walter Milter. Cambridge: Loeb Classical. Vol. V e VI, 1960. 